\title{
Isolated sinusitis sphenoidalis caused by Trichoderma longibrachiatum in an immunocompetent patient with headache
}

\begin{abstract}
Correspondence
László Kredics

kredics@bio.u-szeged.hu
\end{abstract}

Received 20 February 2013

Accepted 7 May 2013

\author{
Etelka Molnár-Gábor, ${ }^{1}$ Ilona Dóczi, ${ }^{2}$ Lóránt Hatvani, ${ }^{3}$ Csaba Vágvölgyi ${ }^{3}$ \\ and László Kredics ${ }^{3}$ \\ ${ }^{1}$ Department of Otorhinolaryngology, Dr. Marron Clinics, Szeged, Hungary \\ ${ }^{2}$ Department of Clinical Microbiology, Albert Szent-Györgyi Clinical Centre, University of Szeged, \\ Szeged, Hungary \\ ${ }^{3}$ Department of Microbiology, Faculty of Science and Informatics, University of Szeged, Szeged, \\ Hungary
}

\begin{abstract}
We present a case of isolated sinusitis sphenoidalis caused by Trichoderma longibrachiatum, an emerging causal agent of fungal infections with an often fatal outcome. A Trichoderma strain was isolated from secretion obtained from the sinus sphenoidalis of a rhinosinusitis patient and identified by sequence analysis of two loci as Trichoderma longibrachiatum from the Longibrachiatum Clade of the genus Trichoderma. T. longibrachiatum can trigger a fatal pathomechanism in immunodeficient patients, but only rarely causes disease in healthy people. The case presented is unique because the patient was not immunocompromised.
\end{abstract}

Certain groups of filamentous fungi have increasing clinical importance as emerging opportunistic pathogens in humans. Species belonging to the genus Trichoderma (Ascomycota, Hypocreales) are also on the growing list of potential fungal pathogens (Kredics et al., 2011). Clinical cases with the involvement of Trichoderma strains known from the literature include skin and lung infections, peritonitis in peritoneal dialysed patients as well as disseminated infections in the liver, brain, heart and stomach of immunocompromised patients (Kredics et al., 2011). Here, we present a case of rhinosinusitis caused by Trichoderma longibrachiatum in an immunocompetent patient with a headache, which was successfully treated by antifungal and surgical therapy.

\section{Case report}

A 29-year-old female patient presented with a frontal and occipital headache for more than 15 years. Two years before admittance to our outpatient clinic, she experienced a worsening nasal blockage that was resistant to conventional medical treatments (antibiotics, antihistamine and decongestant nasal drops). She lost her sense of smell and complained of retrobulbar pressure. She was constantly under otorhinolaryngological care because of pansinusitis and allergic rhinitis. Elevated erythrocyte sedimentation rate and eosinophilia were recorded in her laboratory

Abbreviations: CT, computer tomographic; MIC, minimal inhibitory concentration; ITS, internal transcribed spacer. results, skin prick testing was positive for fungal antigens (Altenaria, Penicillium, Cladosporium), hazelnut and dust mite. The conventional medical treatments were ineffective. Although the patient underwent functional endoscopic sinus surgery (FESS) twice during the year before her presentation, her complaints intensified. The computer tomographic (CT) scan of her head revealed a subtotal inhomogeneous shadow in the sphenoid sinus (Fig. 1a). The magnetic resonance image (MRI) obtained, because of an area suspicious of dehiscence on the cranial wall of the sinus sphenoidalis, showed regular internal and external liquor spaces. The brain substance did not show a pathological picture. Endoscopic investigation revealed swollen, greyish-white nasal mucosa, and a synechia was found between the middle turbinate on the right side and the lateral nasal wall, from behind which a mucinous, yellow punctated secretion was drained. A fungal infection was suspected due to the inhomogeneous shadow in the sphenoid sinus and the swollen, greyish-white nasal mucosa. Since the extended infection process destroyed the upper wall of the sinus sphenoidalis, the extraction of the fungal mass was planned in two steps in order to protect the neighbouring structures. First, the majority of the extraordinarily thick, of partial sawdust consistency, hard fungal mass was extracted through the completely enlarged sphenoidal ostium, leaving behind the core of the mass. Plenty of eosinophil granulocytes were revealed during histological examination of the mass. The clinical specimen was from the mass and inoculated onto chocolate, blood and eosin methylene blue agar plates for 


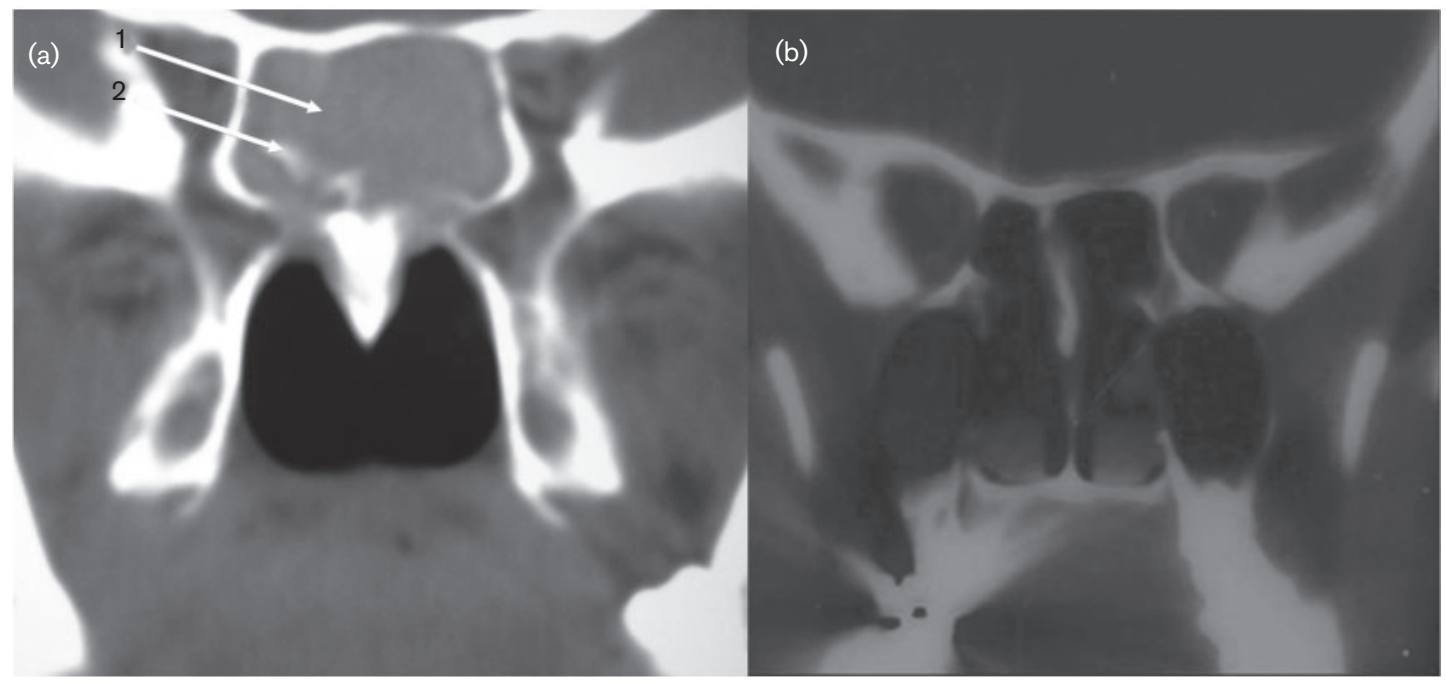

Fig. 1. Computer tomography scan of the sinuses (a) before the first operation: arrow shows subtotal inhomogeneous shadow (arrow 1) with the destruction of the septum in the sinus sphenoidalis (arrow 2); and (b) 2 years after the second operation.

culturing bacteria, and onto Sabouraud chloramphenicol agar plates to recover fungi. Plates were incubated at $37^{\circ} \mathrm{C}$ for 1 day. After the incubation period, Escherichia coli was cultured from the sample. The isolate was sensitive to all antibiotics recommended against this species. Sabouraud medium was incubated further at room temperature. After a $72 \mathrm{~h}$ incubation period counted from the first inoculation, a filamentous fungus was recovered on the medium. The isolate was subcultured and deposited at the Department of Clinical Microbiology, Faculty of Medicine, the University of Szeged as strain 46967/2006.

After surgery, the patient's 10-year-long headache disappeared immediately. Postoperatively, the sphenoid entrance and the sphenoethmoidal recessus were free and without polyps on both sides. Looking into the sphenoid sinus, a mucosa degenerated by polyps could be seen with thick, sticky, yellow-black fungal fragments on a hard, black base on the upper wall. Due to this mycotic residue, the sphenoid sinus was suctioned regularly under endoscopic vision in order to ensure good ventilation. As additional therapy, topical steroid nasal lavage, topical amphotericin B therapy and suction were introduced.

Surgery was carried out a second time after 4 months, during which the well-ventilated, black and hard fungal crust (which by this time was already cracked) was carefully removed by the suctioning equipment. On the basis of the control CT scan (Fig. 1b) and endoscopic picture 2 years after the operation, the patient can be considered now as healthy, without any complaints.

The identification procedure of the fungal isolate was started with macro- and micro-morphological examinations. Colonies were flat, rapidly growing and yellowish-green in colour with green tufts of sporulation on Sabouraud agar. Diffusible yellow pigment was seen around the colonies in the medium. Strain 46967/2006 was able to grow not only at $25{ }^{\circ} \mathrm{C}$, but also at $37^{\circ} \mathrm{C}$ on both minimal medium $\left(10 \mathrm{~g} \mathrm{l}^{-1}\right.$ glucose, $5 \mathrm{~g} \mathrm{l}^{-1}\left(\mathrm{NH}_{4}\right)_{2} \mathrm{SO}_{4}, 5 \mathrm{~g} \mathrm{l}^{-1} \mathrm{KH}_{2} \mathrm{PO}_{4}$ and $1 \mathrm{~g} \mathrm{l}^{-1}$ $\mathrm{MgSO}_{4}$ in distilled water) and yeast extract-glucose medium $\left(1 \mathrm{~g}^{-1}\right.$ yeast extract, $1 \mathrm{~g} \mathrm{l}^{-1}$ glucose in distilled water). This thermotolerant property is a prerequisite of causing infections in the human body. Microscopic structures of the isolate were examined by the adhesive tape technique (St-Germain \& Summerbell, 1996). Hyphae were smooth and septate, conidiophores were long and branched with flask-shaped phialides. Chlamydospores were present. Based on these observations the isolate was identified as a Trichoderma species.

Under the synonym identifier SzMC IM3, strain 46967/ 2006 was identified as T. longibrachiatum based on the sequence analysis of the internal transcribed spacer (ITS) region (ITS1 - 5.8 S rRNA gene - ITS2) of the rRNA gene cluster and fragments of the translation elongation factor $1 \alpha$ (tef1), endochitinase (chi-18-5) and calmodulin (cal1) genes (Druzhinina et al., 2008).

The Etest method (AB BIODISK) for moulds was applied for the determination of minimal inhibitory concentration (MIC) values of amphotericin B, fluconazole, itraconazole, voriconazole and caspofungin according to the manufacturer's instructions. The Etest drug concentrations ranged from 0.016 to $256 \mu \mathrm{g} \mathrm{ml}^{-1}$ for fluconazole, and from 0.002 to $32 \mu \mathrm{g} \mathrm{ml}^{-1}$ for itraconazole, voriconazole, amphotericin $\mathrm{B}$ and caspofungin. The isolate proved to be fully resistant to fluconazole (MIC $>256 \mu \mathrm{g} \mathrm{ml}^{-1}$ ) and itraconazole $\left(\mathrm{MIC}>32 \mu \mathrm{g} \mathrm{ml}^{-1}\right)$. MIC values of amphotericin B, voriconazole and caspofungin were $0.5,0.5$ and $0.25 \mu \mathrm{g}$ $\mathrm{ml}^{-1}$, respectively. 


\section{Discussion}

The first summary about the clinical involvement of the genus Trichoderma was published by Kredics et al. (2003), which was recently followed by a more extensive and updated literature review (Kredics et al., 2011). Opportunistic infections of humans caused by Trichoderma species include rare cases of acute invasive sinusitis and rhinosinusitis, hypersensitivity pneumonitis, peritonitis in continuous ambulatory peritoneal dialysis patients, brain abscess, liver infection, necrotizing stomatitis, skin infection and pulmonary infections of patients with haematological malignancies, disseminated infections of transplant recipients, cerebrospinal fluid infection, endocarditis and otitis externa (Kredics et al., 2011).

A series of clinical Trichoderma isolates were identified based on their morphological characters only, which may result in misidentifications due to the lack of expertise. Therefore the application of molecular techniques, especially DNA barcoding based on sequences of the ITS region (Druzhinina et al., 2005) and a fragment of the tefl gene (Druzhinina et al., 2008) is suggested to confirm the species-level diagnosis of clinical Trichoderma isolates. The application of these methods revealed that the most frequent, almost exclusive causal agent of opportunistic infections within the genus Trichoderma is T. longibrachiatum (Kuhls et al., 1999; Druzhinina et al., 2008), a member of the Longibrachiatum Clade that was recently revised by Samuels et al. (2012), who also provided detailed morphological descriptions of the clade members including T. longibrachiatum. Druzhinina et al. (2008) examined 36 environmental and 15 clinical isolates belonging to $T$. longibrachiatum/Hypocrea orientalis applying multilocus phylogenetic analysis with the involvement of the ITS region and fragments of the tef1, calmodulin (call) and endochitinase (chi-18-5) genes. This study revealed that $H$. orientalis is also a potential opportunistic human pathogen, and that theoretically all strains of $T$. longibrachiatum and $H$. orientalis might be able to cause infections in humans. The Joint Genome Institute of the US Department of Energy has completed the genome sequencing of the $T$. longibrachiatum type strain ATCC 18648 (http://genome. jgi-psf.org/Trilo1/Trilo1.home.html), which will certainly help to reveal the mechanisms of its pathogenicity.

The clinical occurrence of a further four Trichoderma species has also been confirmed by molecular techniques. These are T. harzianum (Guarro et al., 1999; Kantarcioğlu et al., 2009),

T. citrinoviride (Kuhls et al., 1999), T. atroviride (Ranque et al., 2008), and an unknown Hypocreaceae species (Druzhinina et al., 2007), which shares identical ITS and $r p b 2$ (the gene encoding the second largest subunit of RNA polymerase II) sequences with Hypocrea peltata, a recently described sexually reproducing species from the genus Hypocrea, the teleomorph state of Trichoderma (Samuels \& Ismaiel, 2011).

T. longibrachiatum is a commonly occurring, but less abundant component of Trichoderma communities isolated from soil (Druzhinina et al., 2008). However, this species appears to be more abundant in indoor environments such as water-damaged buildings (Mikkola et al., 2012), and it has also been detected in sputum and in the sinus ethmoidalis of healthy humans (Kredics et al., 2011). The genetic identity of environmental and clinical T. longibrachiatum isolates suggests the danger of nosocomial infections and highlights the need for ecological studies of spore dispersal as a source of human mycoses (Druzhinina et al., 2008).

Acute invasive sinusitis caused by $T$. longibrachiatum was reported before in a patient after small bowel and liver transplantation; this was successfully treated with endoscopic sinus operations for debridement, irrigation of the maxillary sinus and oral antifungal treatment with amphotericin B followed by itraconazole (Furukawa et al., 1998). A case of allergic fungal sinusitis due to $T$. longibrachiatum in a patient with a history of atopy and asthma was also documented by Tang et al. (2003). The patient recovered successfully following a combination of sinus lavage, oral corticosteroids, itraconazole, and allergen immunotherapy. Kuhls et al. (1999) briefly mentioned a further case of maxillary sinus infection. Thus, to the best of our knowledge, the presented case is the fourth known sinusitis case worldwide with the involvement of $T$. longibrachiatum.

Although T. longibrachiatum is known as an emerging opportunistic pathogen of mainly immuncompromised patients, the presented case indicates that occasionally this species can cause diseases in immunocompetent patients as well. This report also demonstrates the importance of wide-ranging medical and radiological examinations in cases of chronic headache and nasal congestion. In special cases of severe fungal infection, the appropriately chosen therapy and the consequent postoperative treatment can improve the chances of success.

\section{References}

Druzhinina, I. S., Kopchinskiy, A. G., Komoń, M., Bissett, J., Szakács, G. \& Kubicek, C. P. (2005). An oligonucleotide barcode for species identification in Trichoderma and Hypocrea. Fungal Genet Biol 42, 813-828.

Druzhinina, I. S., LaFe, K., Willinger, B., Komoñ-Zelazowska, M., Ammirati, J., Kubicek, C. P. \& Rogers, J. D. (2007). An unknown Hypocreaceae species isolated from human lung tissue of a patient with non-fatal pulmonary fibrosis. Clin Microbiol Newsl 29, 180-184.

Druzhinina, I. S., Komoń-Zelazowska, M., Kredics, L., Hatvani, L., Antal, Z., Belayneh, T. \& Kubicek, C. P. (2008). Alternative reproductive strategies of Hypocrea orientalis and genetically close but clonal Trichoderma longibrachiatum, both capable of causing invasive mycoses of humans. Microbiology 154, 3447-3459.

Furukawa, H., Kusne, S., Sutton, D. A., Manez, R., Carrau, R., Nichols, L., Abu-Elmagd, K., Skedros, D., Todo, S. \& Rinaldi, M. G. (1998). Acute invasive sinusitis due to Trichoderma longibrachiatum in a liver and small bowel transplant recipient. Clin Infect Dis 26, 487489.

Guarro, J., Antolín-Ayala, M. I., Gené, J., Gutiérrez-Calzada, J., Nieves-Díez, C. \& Ortoneda, M. (1999). Fatal case of Trichoderma 
harzianum infection in a renal transplant recipient. J Clin Microbiol 37, 3751-3755.

Kantarcioğlu, A. S., Celkan, T., Yücel, A., Mikami, Y., Kurugoglu, S., Mitani, H. \& Altas, K. (2009). Fatal Trichoderma harzianum infection in a leukemic pediatric patient. Med Mycol 47, 207-215.

Kredics, L., Antal, Z., Dóczi, I., Manczinger, L., Kevei, F. \& Nagy, E. (2003). Clinical importance of the genus Trichoderma. Acta Microbiol Immunol Hung 50, 105-117.

Kredics, L., Hatvani, L., Manczinger, L., Vágvölgyi, C. \& Antal, Z. (2011). Trichoderma. In Molecular Detection of Human Fungal Pathogens, pp. 509-526. Edited by D. Liu. London, UK: Taylor \& Francis Group.

Kuhls, K., Lieckfeldt, E., Börner, T. \& Guého, E. (1999). Molecular reidentification of human pathogenic Trichoderma isolates as Trichoderma longibrachiatum and Trichoderma citrinoviride. Med Mycol 37, 25-33.

Mikkola, R., Andersson, M. A., Kredics, L., Grigoriev, P. A., Sundell, N. \& Salkinoja-Salonen, M. S. (2012). 20-Residue and 11-residue peptaibols from the fungus Trichoderma longibrachiatum are synergistic in forming $\mathrm{Na}^{+} / \mathrm{K}^{+}$-permeable channels and adverse action towards mammalian cells. FEBS J 279, 4172-4190.

Ranque, S., Garcia-Hermoso, D., Michel-Nguyen, A. \& Dumon, H. (2008). Isolation of Trichoderma atroviride from a liver transplant. J Med Mycol 18, 234-236.

Samuels, G. J. \& Ismaiel, A. (2011). Hypocrea peltata: a mycological Dr Jekyll and Mr Hyde? Mycologia 103, 616-630.

Samuels, G. J., Ismaiel, A., Mulaw, T. B., Szakacs, G., Druzhinina, I. S., Kubicek, C. P. \& Jaklitsch, W. M. (2012). The Longibrachiatum Clade of Trichoderma: a revision with new species. Fungal Divers 55, 77-108.

St-Germain, G. \& Summerbell, R. (1996). Identifying Filamentous Fungi, p. 263. Belmont, CA: Star Publishing Company.

Tang, P., Mohan, S., Sigler, L., Witterick, I., Summerbell, R., Campbell, I. \& Mazzulli, T. (2003). Allergic fungal sinusitis associated with Trichoderma longibrachiatum. J Clin Microbiol 41, 53335336. 